\title{
Проблемы содержания термина «беспомощное состояние» в УК РФ
}

\author{
Н.В. Тыдыкова \\ Алтайский государственный университет \\ пр. Ленина, 61, 656049, Барнаул, Россия. E-mail:academnauka@rambler.ru
}

\begin{abstract}
Статья посвящена исследованию термина «беспомощное состояние», который используется при конструировании многих составов преступлений. Автор анализирует его понимание правоприменительной практикой при квалификации разных составов преступлений. Отмечается, что официальные разъяснения по толкованию этого понятия имеются только применительно к убийству и насильственным половым преступлениям. Обосновывается, что понимание рассматриваемого признака в этих составах принципиально разное. Для квалификации насильственных половых преступлений он имеет более широкое содержание, чем для целей квалификации убийств. Доказывается, что в правоприменительной практике по-разному решаются и иные вопросы квалификации разных составов при его наличии. Это влечет проблему определения содержания термина для других составов, где он также используется, но не разъясняется. Предпринимается попытка дать объяснение разному смысловому наполнению одного и того же термина в зависимости от его места в составах преступлений. Высказано негативное отношение к такому подходу. В качестве разрешения сложившейся проблемы предлагается оставить рассматриваемый термин в таком наименовании лишь в некоторых составах, а в остальных заменить на какой-то иной. Это позволит разные термины наполнить разным смысловым значением. Для единообразия толкования предлагается дать разъяснения в соответствующих по тематике постановлениях Пленума Верховного Суда РФ или в специальном постановлении, посвященном толкованию оценочных признаков. Рекомендуется рассмотреть вопрос о расширении этого понятия для целей квалификации убийств и других насильственных преступлений для обеспечения полноты квалификации и назначения справедливого наказания виновным.
\end{abstract}

Ключевые слова: беспомощное состояние, изнасилование, насильственные действия сексуального характера, убийство, квалифицирующие признаки, оценочные понятия.

\section{Problems of the content of the term «helpless state» in the Criminal Code of Russian Federation}

\author{
N.V. Tydykova \\ Altai State University \\ Lenin St. 61, 656049, Barnaul, Russia. E-mail: academnauka@rambler.ru
}

\begin{abstract}
The article is devoted to the study of the term "helpless state», which is often used in establishing many corpora delicti. The author analyzes its interpreting in the qualification of different corpora delicti in the law enforcement practice. It is not ed that official explanations for the interpretation of this concept are available only in relation to murder and violent sexual crimes. It is proved that the understanding of the characteristic under discussion in these corpora is fundamentally different. For the qualification of violent sexual crimes, it has a wider content than for the qualification of murder. It is proved that in law enforcement practice corpus delicti is qualified differently if there is helpless state. This leads to the problem of deter mining the content of the term for other corpora delicti, where it is also used, but not explained. An attempt is made to explain the different semantic content of the same term, depending on its place in corpus delicti. This approach is viewed here as negative. As a solution to the existing problem, it is proposed to leave the term in question the current name only in some establishments of corpora delicti while replacing it in others. This will allow different terms to be filled with different meanings. For consistency of interpretation, it is proposed to provide explanations in the relevant resolutions of the Plenum of the Supreme Court of the Russian Federation or in a special resolution devoted to the interpretation of evaluative features. It is recomme nded to consider expanding this concept for the purpose of qualifying murders and other violent crimes to ensure ample qualifications of crime $s$ and impose a fair punishment on those guilty.
\end{abstract}


Key words: helpless state, rape, sexual assault, murder, qualifying signs, evaluative concepts.

Термин «беспомощное состояние» потерпевшего в Общей части УК РФ встречается только один раз - в п. «з» ч.1 ст. 63 УК РФ как обстоятельство, отягчающее наказание. В Особенной части УК РФ он называется квалифицирующим приз наком в ряде составов (ст. 105, 110, 110.1, 111, 112, 117, 120, 127.1, 131, 132 УК РФ). Однако определения этого понятия в самом УК РФ нет. Его толкование применительно к составам убийства, изнасилования и насильственных действий сексуального характера дано в соответствующих Постановлениях Пленума Верховного Суда РФ.

Постановление Пленума Верховного Суда РФ от 27.01.1999 N 1 «О судебной практике по делам об убийстве (ст. 105 УК РФ)» В п. 7 разъясняет, что потерпевший в беспомощном состоянии при убийстве - это лицо, неспособное в силу физического или психического состояния защитить себя, оказать активное сопротивление виновному, когда последний, совершая убийство, созна ет э то обстоятельство. К ним могут быть отнесены, в частности, тяжелобольные, престарелые, лица, страдающие психическими расстройствами, лишающими их способности правильно воспринимать происходящее.

Постановление Пленума Верховного Суда РФ от 04.12.2014 N 16 «О судебной практике по делам о преступлениях против половой неприкосновенности и половой свободы личности» в п. 5 говорит, что изнасилование и насильственные действия сексуального характера следует признавать совершенными с использованием беспомощного состояния потерпевшего лица в тех случаях, когда оно в силу своего физического или психического состояния (слабоумие или другое психическое расстройство, физические недостатки, иное болезненное либо бессознательное состояние), возраста (малолетнее или престарелое лицо) или иных обстоятельств не могло понимать характер и значение совершаемых с ним действий либо оказать сопротивление виновному. А в п. 6 того же постановления поясняется, что беспомощным состоянием может быть признано и опьянение, вызванное употреблением алкоголя, наркотических средств или других одурманивающих (психоактивных) веществ, но лишь его степень, которая лишала это лицо возможности понимать характер и значение совершаемых с ним действий либо оказать сопротивление виновному лицу.

Из анализа приведенных определений видно, что трактовка рассматриваемого термина применительно к разным составам разная. Для насильственных половых преступлений Верховный Суд РФ дает более широкое понимание, нежели для убийства. Для квалификации содеянного по статье 105 УК РФ понимание сводится только к неспособности потерпевшего ок азывать сопротивлени е и защищать себя. Применительно к насильственным половым преступлениям можно выделить две разновидности беспомощности: физическую и психическую, т.е. в понятие включаются и те случаи, когда потерпевшие не осознавали характера совершаемых с ними действий.

В практической плоскости это означает, что при квалификации убийств ряд случаев нельзя признать беспомощным состояние м потерпевших. Например, состояние сна, опьянения. Хотя в литературе можно встретить мнение отдельных исследователей о том, что для квалификации всех преступлений рассматриваемый термин должен трактоваться в соответствии с более поздними по времени разъяснениями Верховного Суда РФ, т.е.посвященными преступлениям против половой свободы и неприкосновенности личности [Буликеева 2013:55]. Вряд ли можно согласиться с таким мнением, так как соответствующие разъяснения Верховного Суда имеют тематическую направленность. Более убедительной выглядит позиция тех авторов, которые доказывают, что состояние сна в любых преступлениях должно признаваться беспомощным состоянием потерпевшего, а официальная позиция Верховного Суда РФ требует переосмысления [Балашов 2015: 104-109].

Другим различием является разный подход к малолетним потерпевшим. В соответствии с примечанием к статье 131 УК РФ лица, не достигшие двенадцатилетнего возраста, автоматически признаются находящимися в беспомощном состоянии, поскольку они не могут понимать характер и значение совершаемых с ними действий. В отношении потерпевших с 12 лет такой вопрос решается в каждом конкретном случае индивидуально. В составе убийства малолетний возраст как бы «вынесен за скобки» беспомощного состояния, т.к. в п. «В» ч.2 ст. 105 УК РФ выделен автономно.

Думается, что основная причина разной трактовки этого признака в разных составах в том, что рассматриваемый признак занимает разное место в этих составах. Беспомощное состояние в насильственных половых преступлениях является элементом объективной стороны основного состава, оно является необходимым условием для признания деяния изнасилованием или насильственными действиями сексуального характера (при отсутствии физического насилия или угрозы физическим насилием). Поэтому в его понятие закладываются все возможные варианты, когда посягающему удастся совершить сексуальные действия вопреки (то есть против или помимо) воле потерпевшего, чем причинить вред половой свободе и (или) нормальному нравственному и половому развитию [Тыдыкова 2013: 109-110]. В составе же убийства беспомощное состояние признается квалифицирующим признаком, что предполагает более высокую степень общественной опасности по сравнению с убийством потерпевшего, который не находился в беспомощном состоянии. К беспомощности в составе убийства относятся обстоятельства, которые носят неустранимый в момент посягательства характер (паралич, психическое заболевание), наличие которых не позволяет оказать сопротивление. Дементьев С.И. отмечает, что это состояние заведомо понимает убийца, значит, действует более цинично и нагло, нежели тот, кот орый убивает «из-за угла» [Дементьев 1999: 43]. Если признать неосознание потерпевшим при убийстве характера совершаемых с ним действий (т.е. неосознание им того, что его убивают), то убийство путем выстрела с далекого расстояния, из-за укрытия и т.п. необходимо будет также признавать совершенными при наличии рассматриваемого квалифицирующего обстоятельства, что вряд ли соответствует его сути.

Помимо неодинакового смыслового наполнения термина «беспомощное состояние» в правоприменительной практике поразному решаются и иные вопросы квалификации разных составов при его наличии.

Например, неодинаково решение вопроса о квалификации тех случаев, когда потерпевшие от разных преступлений приводились в беспомощное состояние насильственными действиями виновных. Так, Ф. был признан виновным в совершении изнасилования с применением насилия к потерпевшей и использованием ее беспомощного состояния: он нанес потерпевшей не менее 3 ударов кулаками по голове и 2 - 3 удара по телу, после чего она потеряла сознание. Когда она пришла в себя, то поняла, что лежит на спине на диване, а Ф. совершает с ней половой акт в естественной форме. Кассационная инстанция оставила приговор без изменения [6]. Т.В. Кондрашова также рекомендует указывать на оба обязательных признака (применение физического насилия и использование беспомощного состояния потерпевшей) также и в том случае, когда для дальнейшего совершения с ней полового акта потерпевшая была приведена в бессознательное состояние путем введения в ее организм одурманивающих веществ [Коробеев 2008: 513-514]. Эта позиция кажется разумной: указание и того и другого альтернативных признаков объективной стороны состава на квалификацию не влияет, но является обязательным условием для назначения справедливого наказания. В литературе приводятся и 
другие примеры из практики, когда правоприменитель идет по тому же пути [Безматерных 2018:145]. Однако при квалификации убийств если беспомощное состояние потерпевших было результатом примененного виновным насилия, то этот признак вообще вменяться не должен. Так, по одному из дел Верховный Суд РФ указал, что необходимо исключить осуждение по п. «в» ч. 2 ст. 105 УК РФ, поскольку потерпевший оказывал осужденным сопротивление, в бессознательное состояние он был приведен в процессе реализации ими умысла на его убийство, а потому бессознательное состояние потерпевшего в данном случае нельзя отнести к беспомощному, дающему основание для квалификации действий осужденныхпо п. «в»ч. 2 ст. 105 УК РФ [9].

Такую разницу в подходах снова можно объяснить местом рассматриваемого признака в составах. Так как в составах насильственных половых преступлений беспомощное состояние - один из альтернативных (наряду с насилием и угрозой его применения) способов совершения действия сексуального характера, то необходимо указывать все признаки для полного описания содеянного. Тот факт, что беспомощное состояние стало причиной примененного насилия, также особенного значения не имеет, так как насилие в этих составах является способом и даже в какой-то степени сутью, содержанием преступления. В таком варианте совершения этих преступлений не имеет значения, насилие стало способом совершения желаемых действий непосредственно, или стало способом приведения в беспомощное состояние, которое уже и позволило совершить те самые желаемые действия с потерпевшими. Субъективно можно предположить, что второй вариант обладает большей общественной опасностью, так как нахождение потерпевших в таком состоянии само по себе может негативно сказываться на здоровье потерпевших (помимо примененного к ним насилия). Поэтому думается оправданным учитывать это обстоятельство при назначении наказания. Что касается убийства, то насилие и составляет основное содержание деяния как признака объективной стороны этого состава. Вероятно, по этой причине Верховный Суд РФ посчитал, что на квалификацию не должно оказывать влияние то обстоятельство, что в процессе примененного насилия, направленного на лишение жизни, потерпевший в какой-то момент времени до лишения жизни оказывался в том состоянии, когда не был способен защитить себя. Впрочем, к такой позиции Верховного Суда РФ можно относиться по-разному.

В литературе высказывается позиция отом, что если в разных случаях необходимо разное смысловое наполнение одного и того же термина, то, возможно, стоит в каком-то из составов заменить этот термин на другой. Например, в составе квалифицированного убийства использовать термин «заведомое физическое или психическое бессилие потерпевшего, не связанное с действиями субъекта посягательства» [Барышева 2016: 120]. Позиция кажется вполне разумной, хотя вопрос о наименовании требует самостоятельного обсуждения. Однако высказываются и другие предложения для решения рассматриваемой проблемы. Например, предлагается сформулировать единое понимание этого признака во всех составах преступлений [Шикула 2018: 33]. Также отмечается, что УпК РФ использует рассматриваемый термин и тоже не раскрывает его содержания, что создает трудности для правоприменительной практики [Карпушов 2018: 23], в связи с чем отдельные исследователи даже говорят о необходимости междисциплинарных исследований для решения вопроса [Шикула 2016: 22]. Думается, что при выборе пути совершенствования уголовного закона необходимо решить вопрос о необходимом содержании рассматриваемого термина в разных составах преступлений и для тех составов, где содержание одинаково, оставить один термин. Для тех случаев, которые потребуют иного содержания, необходим иной термин.

Особенно острой является сложившаяся проблема в свете необходимости понимания рассматриваемого термина и в иных составах, (например, в составе, предусмотренном ст. 111 УК РФ), для которых отсутствуют официальные разъяснения по его пониманию. Так как «беспомощное состояние» в составах УК РФ является не единственным оценочным понятием, трактовка которого вызывает трудности в правоприменительной практике, то, возможно, целесообразным было бы принятие Верховным Судом РФ специального постановления, посвященного содержанию такихтерминов. На необходимость такого постановления отдельные авторы указывают и в свете анализа проблем такого оценочного понятия, как «особая жестокость» [Меньшикова 2014: 69; Серегина 2018: 271].

Таким образом, понятие беспомощного состояния имеет устоявшееся понимание только для квалификации убийств и насильственных половых преступлений. К сожалению, Верховный Суд РФ дает разное толкование одного и того же понятия в этих двух случаях. Толкование этого понятия для других составов отсутствует, что создает серьезную проблему для правоприменительной практики. Для ее решения требуется комплексное решение с учетом потребностей квалификации всех преступлений, где этот термин используется.

\section{Литература}

1. Балашов С.М. Сон как состояние беспомощности / Бизнес в законе. Экономико-юридический журнал. 2015. - № 3. - С. 104-109.

2. Барышева К.А. Коллизии определения наличия признака беспомощности потерпевшего в некоторых составах преступлений / Право. Журнал Высшей школы экономики. - 2016. - № 4. - С. 118-128.

3. Буликеева Д.Ж. Проблемы применения квалифицирующего признака «иное лицо, заведомо для виновного находящееся в беспомощном состоянии» / Вестник Челябинского государственного университета. - 2013. - № 17 (308). - С. 54-57.

4. Дементьев С. Понятие беспомощного и бессознательного состояния / Российская юстиция. - 1999. - N 1. - С. 43.

5. Карпушов М.А. Понятие «беспомощное состояние» как одно из оснований возникновения обязательного представительства потерпевшего в уголовном судопроизводстве / Адвокатская практика. - 2018. - N 1. - С. 23 - 26.

6. Кассационное определение Судебной коллегии по уголовным делам Санкт-Петербургского городского суда по делу $\mathrm{N} 22$ 506/2011 (N 1-539\2010r.). URL: https://rospravosudie.com/

7. Безматерных М.А., Качина Н.В. Совместное использование признаков «применение насилия» и «использование беспомощного состояния потерпевшего (потерпевшей)» при квалификации деяний, предусмотренных статьями 131 и 132 УК РФ/ Актуальные проблемы российского права. - 2018. - № 12. - С. 142-147.

8. Меньшикова А.Г. Соотношение понятий «особая жестокость», «издевательство» и «мучения» применительно к п. «в» ч. 2 ст. 112 УК РФ / Российский юридический журнал. - 2014. - N 4. - С. 69.

9. Определение Верховного Суда РФ от 10.09.2007 по делу N 78-007-52CП // URL: http://www.pravosudie.biz/403730.

10. Полный курс уголовного права: В 5 т. / под ред. А.И. Коробеева. СПб.: Юридический центр Пресс, 2008. Т. ІІ: Преступления против личности. С. 513 - 514.

11. Серегина Е.В., Казанова Т.A. Сложности уголовно-правовой оценки признаков преступлений, совершенных с особой жестокостью / Международный журнал гуманитарных и естественных наук. - 2018. - № 5. - Том. 2. - С. 271.

12. Тыдыкова Н.В. Уголовно-правовая характеристика и вопросы квалификации насильственных половых преступлений: монография. - М., 2013. - 192с. 
13. Шикула И.Р. Дискуссионные вопросы определения беспомощного состояния потерпевшего в уголовном законодательстве / Актуальные вопросы борьбы с преступлениями. -2016. - №2. - С. 20-22.

14. Шикула И.Р. К вопросу определения уголовно-правовых критериев оценки беспомощного состояния потерпевшего / Актуальные проблемы современности: наука и общество. - 2018. - № 1 (18). - С. 33-35.

\section{References}

1. Balashov, S. M. (2015). Dream as a state of helplessness. Business is legal. Economic and legal journal, 3, 104-109 (in Russian).

2. Barysheva, K. A. (2016). Conflicts of definition of existence of a sign of helplessness of the victim in some structures of crimes. The Law. Journal of Higher School of Economics, 4, 118-128 (in Russian).

3. Bulycheva, D. J. (2013). The problem of applying the aggravating circumstance "other person known to the perpetrator in a hel pless state". Bulletin of the Chelyabinsk State University, 17(308), 54-57 (in Russian).

4. Cassation determination of Judicial Board on criminal cases of the St. Petersburg City Court. (2011). The case No 22-506/2011 (N 1539 2010). Available from: https://rospravosudie.com/ (in Russian).

5. Dement'ev, S. (1999). The Notion of a helpless and unconscious condition. The Russian justice, 1, 43 (in Russian).

6. Crimes against the person. (2008). Pp. 513-514. In Full course of criminal law. A. I. Korobeev (Ed.). St. Petersburg, Law center Press (in Russian).

7. Korpusov, M. A. (2018). The Concept of "helpless state" as one of the grounds for the compulsory representation of victims in criminal proceedings. Law practice, 1, 23-26 (in Russian).

8. Menshikov, A. G. (2014). The relationship between the concepts of "particular cruelty", "abuse" and "torture" in relation to paragraph "C" of part 2 of article 112 of the criminal code of Russian Federation. Russian law journal, 4, 69 (in Russian).

9. Mezmaterykh, M. A., Kachina, N. I. (2018). Joint use of signs of "use of violence" and "use of the helpless state of the victim (victim)" in the qualification of acts provided for in articles 131 and 132 of the criminal code. Actual problems of Russian law, 12, 142-147 (in Russian).

10. Seregina, E. V., Casanova, T. A. (2018). Difficulties of criminal-legal assessment of signs of crimes committed with special cruelty. International journal of Humanities and Natural Sciences, 5(2), 271 (in Russian).

11. Shikula, I. R. (2016). Debatable questions of definition of a helpless condition of the victim in the criminal legislation. Actual questions of fight against crimes, 2, 20-22 (in Russian).

12. Shikula, I. R. (2018). To the question of determining the criminal law criteria for assessing the helpless state of the victim. Actual problems of our time: science and society, 1(18), 33-35 (in Russian).

13. The determination of the Supreme Court of the Russian Federation dated 10.09.2007 in the case of N 78-007-52Cח. Available from: http://www.pravosudie.biz/403730/ (in Russian).

14. Tydykova, N.V. (2013). Criminal law characterization and qualification of violent sexual offenses: a monograph. Moscow (in Russian).

\section{Citation:}

Тыдыкова Н.В. Проблемы содержания термина «беспомощное состояние» в УК РФ. // Юрислингвистика. - 2019. - 13. - С. 10-13.

Tydykova, N.V. (2019). Problems of the content of the term «helpless state» in the Criminal Code of Russian Federation.

Legal Linguistics, 13, 10-13.

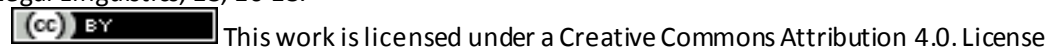

